\title{
Cumulative clinical experience with use of insulin lispro: critical appraisal, role in therapy, and patient considerations
}

This article was published in the following Dove Press journal:

Diabetes, Metabolic Syndrome and Obesity:Targets and Therapy

9 January 2012

Number of times this article has been viewed

J Uy

L Fogelfeld

Y Guerra

Division of Endocrinology, Diabetes and Metabolism, John H Stroger Jr Hospital of Cook County, Chicago; Department of Endocrinology,

Diabetes and Metabolism, Rush University Hospital, Chicago, IL, USA
Abstract: We have now at our disposal the new rapid-acting insulin analogs, of which insulin lispro was the first to become commercially available. While the differences in pharmacokinetic and pharmacodynamic characteristics are indisputable, the clinical benefits attained by these changes have not been as clear. In the present review, we discuss the structure, pharmacology, and landmark studies related to insulin lispro. The clinical characteristics of insulin lispro are compared with those of insulin regular and other insulin analogs in different clinical situations. Also included are the aspects of quality of life and cost-effectiveness that may modify the modern practitioner's decision to adopt one type of insulin over another.

Keywords: insulin lispro, rapid-acting, insulin, analog

\section{Background}

We have now at our disposal the new rapid-acting insulin analogs which mimic the first phase of pancreatic insulin secretion in response to a meal. These rapid-acting insulin analogs, when combined with long-acting insulin or used in a continuous subcutaneous insulin infusion pump, mimic the pattern of endogenous pancreatic insulin secretion both in the basal and prandial states. This is the "basal-bolus" therapy paradigm and is the closest physiologically matched insulin replacement therapy among the injectable forms. Basal-bolus therapy allows tighter blood sugar control and possibly reduces the risk of severe hypoglycemia associated with conventional insulin therapy using human regular insulin.

At present, there are three rapid-acting insulin analogs used clinically and available on the market. These insulin analogs are lispro (Eli-Lilly), aspart (Novo-Nordisk), and glulisine (Sanofi-Aventis). They are marketed, respectively, under the brand names Humalog $^{\circledR}$, Novolog $^{\circledR}$, and Apidra ${ }^{\circledR}$. All of the rapid-acting insulin analogs were developed using recombinant DNA technology by modifying one or more amino acids in the insulin molecule. This modification led to faster subcutaneous absorption compared with human regular insulin. All of the insulin analogs are approved for use subcutaneously using a pen device or syringe as well as insulin pumps. Among these commercially available rapid-acting insulin analogs, insulin lispro was the first to be developed and has been available in the US since 1996. Insulin lispro will be the topic of this review.

Human regular insulin exists as hexamers in solution. Once injected subcutaneously, the hexamers dissociate into dimers and monomers before being absorbed into the systemic circulation. Insulin lispro differs from human regular insulin in that once injected
Correspondence:Yannis Guerra

1900 W Polk Street, Suite 805,

Chicago, IL 60612, USA

$\mathrm{Tel}+\mathrm{I} 3128640552$

Fax + I 3128649735

Email yannisguerra@yahoo.com 
subcutaneously, it dissociates faster into monomers compared with human regular insulin. As such, it results in an earlier and much greater peak than human regular insulin. This property is shared by insulin aspart as well as glulisine. In insulin lispro, this property is achieved by transposition of the amino acid, proline, at position 28 of the $\mathrm{B}$ chain to that of lysine at position 29 (see Figure 1). This change causes insulin lispro to have fewer tendencies for self-association by primarily disrupting the formation of dimers, causing it to dissociate more quickly into monomers once injected into the subcutaneous tissue. ${ }^{1}$ Although this amino acid transposition alters the structure of native human insulin, leading to faster dissociation of the hexamer molecule into monomers, it does not alter the capacity of insulin lispro to bind to the insulin receptor and to dissociate from the insulin receptor when compared with human regular insulin. It is worth mentioning that the two other rapid analogs also have structural changes that allow the rapid onset of action seen with insulin lispro. In insulin aspart, proline is substituted with the charged aspartic acid at B28 position, and in insulin glulisine, asparagine at position B3 is replaced by lysine, and lysine in position B29 is replaced by glutamic acid.

\section{Pharmacokinetics and pharmacodynamics}

The development of rapid-acting insulin analogs was driven by the need to change the parameters controlling the selfassociation of the insulin hexamers. This would, in principle, affect the speed of absorption of insulin and its pattern of activity in the body. From the first studies published about insulin lispro in the 1990s, the difference was clear. Studies in healthy volunteers showed that the insulin lispro concentration peaked at almost twice the concentration of human regular insulin and did so in half the time (see Figure 2 for details).

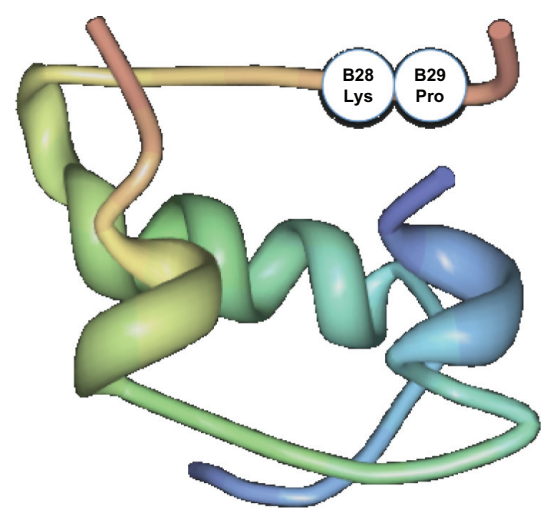

Figure I Structure of insulin lispro, showing the amino acid modifications that produce insulin lispro.

Modified from PDB ID: 3E7Y Timofeev VI, Baidus AN, Kislitsyn YA, Juranova IP.
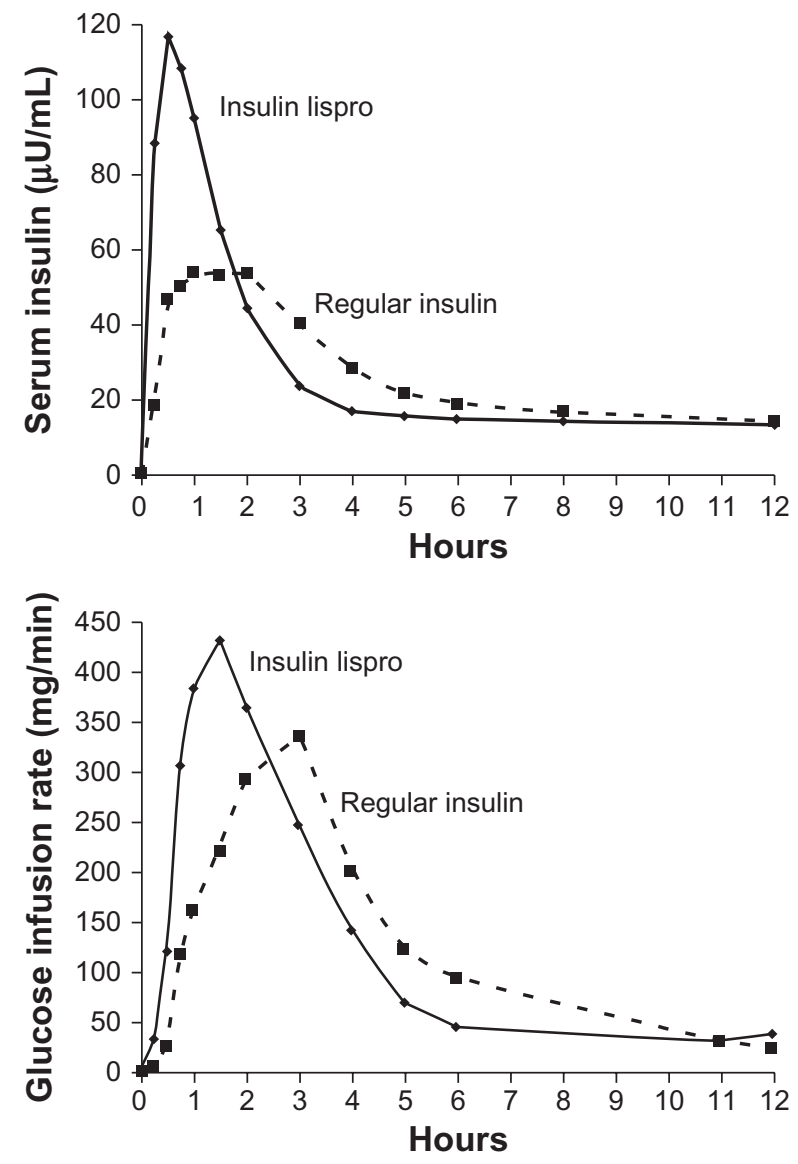

Figure 2 (A) Concentration of insulin lispro reaches its peak in half of the time that human regular insulin takes to reach its peak. (B) The highest glucose infusion rate is reached in half of the time for insulin lispro compared with human regular insulin. Reprinted with permission from Holleman MD, Hoekstrra JBL. Insulin Lispro. N Engl J Med. 1997;337:176-183.67

Insulin lispro has a shorter half-life compared with human regular insulin, and it was originally thought that this could affect its potency. However, glucose clamp studies showed that both the total infused glucose $(450.8 \pm 161.8 \mathrm{mmol}$ versus $454.7 \pm 167.4 \mathrm{mmol}$ ) and the area under the curve of the glucose levels over time were equivalent for both insulin lispro and human regular insulin ${ }^{2}$ (see Table 1 for details).

In subsequent years, with the development of other insulin analogs, a number of studies compared the respective characteristics of the various analogs in different clinical settings. One study ${ }^{5}$ observed that after subcutaneous injection of either analog, insulin lispro showed more rapid absorption, reached a peak concentration earlier ( $40 \pm 3$ minutes versus $49 \pm 3$ minutes; $P=0.01)$ and showed a more rapid decline than insulin aspart (decrease of free insulin concentration from peak concentration to $50 \%$ of the maximum concentration, $113 \pm 10$ minutes versus $154 \pm 14$ minutes; $P=0.02$ ) The authors of this study believed this finding may be of clinical importance. 
Table I Comparison of human regular insulin and insulin lispro ${ }^{2-4}$

\begin{tabular}{llll}
\hline & & Human regular insulin (SC) & Insulin lispro (SC) \\
\hline Pharmacokinetics & Maximum serum insulin level (PM) & $308 \pm 132$ & $698 \pm 227$ \\
& Time to peak concentration (minutes) & $101 \pm 40$ & $42 \pm 20$ \\
& Area under the serum insulin concentration & $72.7 \pm 12.3$ & $71.4 \pm 14.6$ \\
& versus time curve (nmol $\cdot \mathrm{min}^{-1} \cdot \mathrm{L}^{-1}$ ) & & $5-15$ \\
Pharmacodynamics & Onset of action (minutes) & $30-60$ & $0.5-1.5$ \\
& Peak of action (hours) & $2-3$ & $4-5$ \\
& Duration of action (hours) & $6-10$ & $3.10 \pm 1.19$ \\
& Maximum glucose infusion rate (mmol/minute) & $2.20 \pm 1.01$ & $99 \pm 39$ \\
Receptor affinity & Time to maximum glucose infusion rate (minutes) & $179 \pm 93$ & $450.8 \pm 161.8$ \\
and mitogenicity & Total amount of glucose infused (mmol) & $454.7 \pm 167.4$ & $84 \pm 6$ \\
& Insulin receptor affinity (\%) & 100 & $100 \pm 11$ \\
& Insulin receptor off rate (\%) & 100 & $82 \pm 3$ \\
& Metabolic potency (\%) & 100 & $156 \pm 16$ \\
& IGF-I receptor potency (\%) & 100 & $66 \pm 10$ \\
\hline
\end{tabular}

Abbreviations: IGF-I, insulin growth-like factor I; SC, subcutaneous.

An randomized double-blind study in healthy males comparing insulin lispro and $\operatorname{aspart}^{6}$ showed a 10-minute difference in the time to maximal reduction, favoring insulin aspart, but no difference in the glucose control response. Two studies done in patients with type 1 diabetes mellitus, showed very similar peak times for both insulin aspart and lispro (approximately 40 minutes in both studies) and time to reach $50 \%$ of the peak (approximately 20 minutes). The consistent results over two separate studies point towards a real biological equivalence between these two insulin analogs.

Another study investigated if there was a difference in the metabolic effects between insulin aspart and lispro among patients with type 1 diabetes mellitus. After subcutaneous injection of an equal amount of each insulin into the same patients, no statistically significant difference was found between the two insulin analogs in terms of its effect on carbohydrate metabolism (glucose uptake, glucose oxidation, and endogenous glucose production) and lipid metabolism (plasma free fatty acid, ketone body levels, and free fatty acid oxidation). There were also no significant changes in c-peptide and glucagon levels in this study. ${ }^{8}$

Among healthy nondiabetic volunteers, it has been shown that insulin glulisine is biochemically equivalent to insulin lispro, but it has a faster onset of action than insulin lispro in the first hour after subcutaneous injection (area under the curve $0-1$ hour $[\mathrm{mg} / \mathrm{kg}] 69.22 \pm 38.59$ for insulin glulisine versus $45.95 \pm 28.84 \mathrm{mg} / \mathrm{kg}$ for insulin lispro). ${ }^{9}$ This effect was observed independent of body mass index and dose, and was observed in Caucasian and Chinese volunteers. ${ }^{9,10}$ During an euglycemic glucose clamp trial among patients with type 1 diabetes mellitus, insulin lispro and glulisine had similar effects on suppression of endogenous glucose production, as well as glucose uptake and free fatty acid, glycerol, and lactate levels compared with human regular insulin.

Another aspect of the comparative studies was the use of insulin lispro as part of a combination regimen (rapidacting insulin/basal insulin). When mixed with human neutral protamine hagedorn insulin (NPH), insulin lispro is not stable over time, precluding prolonged storage of this mixture. Because of this, insulin lispro has been coupled with protamine to produce neutral protamine lispro. Its pharmacokinetic and glucodynamic characteristics are comparable with those of neutral protamine hagedorn when tested in a glucose clamp study that involved eight healthy volunteers, ${ }^{11}$ although those given neutral protamine lispro initially had a slightly greater glucose requirement than those given neutral protamine hagedorn. ${ }^{12}$ The difference was small and the clinical significance is probably not significant.

In comparative studies that utilized insulin lispro as part of a combination regimen (rapid-acting insulin/basal insulin), an euglycemic glucose clamp study using healthy subjects that compared different concentrations of insulin lispro/neutral protamine lispro $(25 / 75,50 / 50$, and $75 / 25)$ showed that independently of the mixture, the maximal metabolic effect was reached after 2 hours, its amplitude determined by the relative amount of rapid-acting insulin lispro. The glucose requirement after 6 hours was affected by the concentration of neutral protamine lispro, but the area under the curve at 6 hours was equivalent between all the preparations. ${ }^{13}$ 
There are some differences in the interaction of insulin lispro with the insulin-like growth factor 1 (IGF-1) receptor in comparison with human regular insulin and other analogs. The affinity of insulin lispro for the IGF-1 receptor is 1.5fold that of human insulin, ${ }^{14}$ but its mitogenic potential is slightly less than that of human insulin when evaluated using human osteosarcoma cells (Saos/B10), ${ }^{4}$ indicating that the slightly elevated IGF-1 receptor affinity is not sufficient to provide a mitogenic stimulus, at least with Saos/B10 cell lines. Using human mammary epithelial cells provided similar results. ${ }^{15}$ The differences in IGF-1 receptor binding affinity can be accounted for by the structural amino acid transposition changes that increase the homology of insulin lispro to IGF-1. ${ }^{14}$

In summary, insulin lispro has been shown to have a more rapid concentration peak and a shorter half-life compared with human regular insulin. This change results in a shorter time to maximal glucose reduction and similar potency, with a shorter duration of action compared with human regular insulin. There are no major differences in comparison with other rapid-acting insulin analogs.

\section{Clinical studies}

In trials that compare insulin regimens, hemoglobin A1c $\left(\mathrm{HbA}_{1 \mathrm{lc}}\right)$ measurement, fasting and postprandial glucose, and hypoglycemia occurrence are the common measurable outcomes. $\mathrm{HbA}_{1 \mathrm{c}}$ reflects the overall glycemic exposure of the preceding 3 months. It is influenced by both fasting blood glucose as well as postprandial plasma glucose values. At higher $\mathrm{HbA}_{1 \mathrm{c}}$ values $(>8.4 \%)$, the fasting plasma glucose contribution predominates, and at lower $\mathrm{HbA}_{1 \mathrm{c}}$ the postprandial glucose contribution predominates. ${ }^{16}$ The introduction of the rapid-acting analogs, by the nature of their rapid onset of action, would better control blood glucose excursions after meals and, in theory, should improve $\mathrm{HbA}_{1 \mathrm{c}}$ in the setting of patients with adequate basal insulin coverage (ie, reasonable fasting glucose levels).

As shown in Table 1, human regular insulin, when compared with insulin lispro (as well as insulin aspart and glulisine) has a slower onset of activity (30-60 minutes) and has a longer duration of action (6-8 hours). Because of its slower onset of action, human regular insulin needs to be administered at least 30 minutes before meals to match the blood glucose excursion during meals. In reality, most patients do not follow the correct timing of human regular insulin administration in relation to a meal. ${ }^{17}$ Because of its longer duration of action, human regular insulin can lead to late postprandial hypoglycemia. In contrast, insulin lispro (as well as insulin glulisine and aspart) can be injected immediately before, during, or immediately after meals because it has a faster onset of action. This property of the rapid-acting insulin analogs offers the greatest advantage to patients in terms of practicality and flexibility that otherwise cannot be achieved with the human regular insulin formulation.

Below are described the comparative efficacy and safety studies of insulin lispro versus human regular insulin and other rapid-acting analogs.

\section{Insulin regular versus lispro}

Numerous studies have shown that the rapid-acting insulin analogs achieve lower postprandial blood glucose levels when compared with human regular insulin. ${ }^{18-21} \mathrm{~A}$ review by Gough $^{22}$ showed that rapid-acting insulin analogs compared with human regular insulin resulted in consistently lower postprandial blood glucose levels. In patients with type 1 diabetes mellitus, postprandial blood glucose levels were 0.6-2.0 $\mathrm{mmol} / \mathrm{L}$ lower in subjects on insulin lispro compared with those on human regular insulin. Among patients with type 2 diabetes mellitus on a basal-bolus regimen, postprandial blood glucose levels were $48 \%-53 \%$ lower compared with human insulin, with no significant or fewer episodes of hypoglycemia in favor of insulin lispro.

In one of the largest trials that has utilized insulin lispro in patients with type 1 diabetes mellitus, insulin lispro has been shown to achieve mean overall postprandial blood glucose levels that were significantly lower than for human regular insulin (postprandial rise in serum glucose was reduced at one hour by $1.3 \mathrm{mmol} / \mathrm{L}$ and at 2 hours by $2.0 \mathrm{mmol} / \mathrm{L}$ in patients treated with insulin lispro $[P<0.001])$. The reduction in postprandial blood glucose was also shown in other studies. ${ }^{19,20,23}$ The same is true for patients with type 2 diabetes mellitus, either as part of oral therapy or patients already on insulin therapy. ${ }^{19,24-26}$ The reduction in postprandial blood glucose levels was seen whether insulin lispro was given as part of a basal-bolus regimen, premixed insulin with human or analog insulin, or in combination with oral agents.

Despite reduction in postprandial hyperglycemia, a Cochrane meta-analysis ${ }^{27}$ that compared rapid-acting insulin analogs with human regular insulin found a weighted mean difference in $\mathrm{HbA}_{1 \mathrm{c}}$ of only $-0.1 \%$ in favor of rapid-acting analogs in patients with type 1 diabetes mellitus. There was no difference in $\mathrm{HbA}_{1 \mathrm{c}}$ in patients with type 2 diabetes mellitus. In this meta-analysis, 49 randomized controlled trials were included, and 37 studies used insulin lispro. In assessing the $\mathrm{HbA}_{1 \mathrm{c}}$ reduction in patients with type 1 diabetes mellitus, 22 studies were included in the analysis, of which 16 studies 
compared insulin lispro with human regular insulin. The trials included showed significant heterogeneity $(P=0.02)$. The analysis for type 2 diabetes mellitus included five studies. The meta-analysis also reported that fewer severe hypoglycemic episodes occurred among patients with type 1 diabetes mellitus given rapid-acting insulin compared with those who were given human regular insulin. The incidence of severe hypoglycemia was 21.8 (median) episodes per 100 personyears for rapid-acting insulin analogs versus 46.1 for human regular insulin. For patients with type 2 diabetes mellitus, the incidence of severe hypoglycemia was 0.3 (median) episodes per 100 person-years for insulin analogs and 1.4 for human regular insulin.

Additional and more recent studies have focused on the impact of the basal-bolus regimen approach in patients with type 1 diabetes mellitus, and these were compared in a 2010 meta-analysis. ${ }^{28}$ In this meta-analysis, 28 articles were included, of which 17 studies compared insulin lispro with human regular insulin. The majority of the studies used neutral protamine hagedorn as the basal insulin. Overall, the average change in $\mathrm{HbA}_{1 \mathrm{c}}$ from baseline to study end for rapidacting insulin analogs compared with human regular insulin was $-0.16 \%$ and $-0.08 \%$, respectively, with a tendency towards greater $\mathrm{HbA}_{1 \mathrm{c}}$ improvement with rapid-acting insulin analogs. The authors of this meta-analysis postulated that the minimal improvement in $\mathrm{HbA}_{1 \mathrm{c}}$ may have been due to the use of neutral protamine hagedorn as the basal insulin in most of the studies, as well as the limitations of the studies included, which were primarily aimed at demonstrating noninferiority of the rapid-acting insulin analogs. The authors of this metaanalysis did not pool the data for incidence of hypoglycemia, but most of the studies reported lower or similar incidences of total or nonsevere hypoglycemia episodes with rapid-acting insulin analogs compared with human regular insulin. The prevalence of severe hypoglycemia in the included studies was low. It should be borne in mind that the rates of hypoglycemia in the studies included in this meta-analysis tended to be lower for rapid-acting insulin analogs, and this was accompanied by $\mathrm{HbA}_{1 \mathrm{c}}$ improvement, albeit minimal.

In a review that compared an all-analog insulin regimen with an all-human insulin regimen, $\mathrm{HbA}_{1 \mathrm{c}}$ reduction in favor of all-analog insulin was seen in two studies $(7.88 \%$ versus $8.11 \% ; P<0.001$ in favor of aspart/detemir and $7.5 \%$ versus $8.0 \% ; P<0.001$ in favor of glargine/lispro). ${ }^{29,30}$ These two studies also showed a similar or decreased overall incidence (21\% reduction, $P=0.036$ ) of hypoglycemia as well as nocturnal hypoglycemic events (up to a $55 \%$ reduction, $P<0.001)$. A third study ${ }^{31}$ did not show a significant difference among those given glargine/lispro and neutral protamine hagedorn/human regular insulin in terms of an $\mathrm{HbA}_{1 \mathrm{c}}$ reduction, but did show a decrease in nocturnal hypoglycemic events by $43 \%$ in favor of insulin lispro. Several studies have also shown a lower occurrence of hypoglycemia with the use of rapid-acting insulin analogs compared with human regular insulin. . $^{18,19,31,32}$

Perhaps the greatest benefit of rapid-acting insulin analogs compared with human regular insulin, in terms of $\mathrm{HbA}_{1}$ reduction and occurrence of hypoglycemia, comes from data derived from its use among insulin pump users with type 1 diabetes mellitus. It has been shown in continuous subcutaneous insulin pump users that insulin lispro provides a similar or greater reduction of $\mathrm{HbA}_{1 \mathrm{c}}$, with no increase or less incidence of hypoglycemia compared with human regular insulin. ${ }^{33-37}$ In one of these studies, ${ }^{37}$ the reduction in $\mathrm{HbA}_{1 \mathrm{c}}$ was $-0.62 \% \pm 0.13 \%$ for insulin lispro compared with $-0.09 \% \pm 0.15 \%$ for human regular insulin. The incidence of hypoglycemia with blood glucose $<3.0 \mathrm{mmol} / \mathrm{L}$ did not differ significantly between the two insulins, but the incidence of blood glucose $<2.0 \mathrm{mmol} / \mathrm{L}$ was significantly reduced with insulin lispro $(0.05 \pm 0.05$ versus $0.47 \pm 0.19$ per month, $P<0.05)$. The theoretical disadvantage of insulin lispro given by continuous subcutaneous insulin pump infusion, especially among patients with type 1 diabetes mellitus, is the propensity to develop diabetic ketoacidosis sooner if the pump is disconnected for whatever reason. This is because of the shorter duration of action of insulin lispro. However, this was not seen in a study by Attia et al, who showed that the rate of rise in plasma glucose or serum ketone formation is similar between human regular insulin and insulin lispro when the pump is disconnected for 6 hours. ${ }^{38}$

The use of insulin lispro in an inpatient setting in a general medicine ward has been investigated recently. The use of prandial human regular insulin was compared with rapid-acting insulin analogs in regards to the timing of insulin delivery (target time) in relation to meals, patient safety (mostly rates of hypoglycemia), and glucose control. A higher rate of target time in the insulin lispro group was achieved compared with the human regular insulin group $(88.9 \%$ versus $70.1 \%, P<0.001)$. The rate of hypoglycemia was lower for insulin lispro compared with human regular insulin $(1.85 \%$ versus $15 \%, P<0.001)$. The rate of hyperglycemia (blood glucose $>180 \mathrm{mg} / \mathrm{dL}$ ) was similar in both groups (68.2\% versus $59.8 \%, P=0.224)$, but severe hyperglycemia $(>300 \mathrm{mg} / \mathrm{dL})$ was higher for the insulin lispro group (28.9\% versus $12.9 \%, P=0.003) .{ }^{39}$ Among hospitalized patients, whose meal intake can be unpredictable for various 
medical and logistical reasons, the use of rapid-acting insulin analogs, allowing nurses to time the injections at the start of each meal, may lead to better patient outcomes than the use of human regular insulin.

\section{Insulin lispro versus aspart}

Among patients with type 1 diabetes mellitus on continuous subcutaneous insulin infusions, one study ${ }^{35}$ showed no differences in $\mathrm{HbA}_{1 \mathrm{c}}$ or rates of hypoglycemic episodes per patient per month between those using human regular, aspart, or lispro insulins, although they noted a trend towards slightly lower rates and number of hypoglycemic episodes in favor of insulin aspart.

Another study involving patients with type 1 diabetes mellitus on continuous insulin infusion ${ }^{40}$ assessed the effect of both insulin lispro and aspart on glucose variability after each was given as a normal-wave bolus 15 minutes before a standard meal, as measured using a continuous glucose monitoring system. This was a randomized, controlled, open-label, crossover clinical trial. The result of this study showed that both insulin lispro and aspart comparably reduced the early postprandial glucose value (30 and 60 minutes), but the late postprandial glucose value (90 and 120 minutes) continued to decrease more with insulin lispro, with significantly lower levels compared with insulin aspart $(9.3 \pm 36.6 \mathrm{mg} / \mathrm{dL}$ at 90 minutes; $-12 \pm 43.6 \mathrm{mg} / \mathrm{dL}$ at 120 minutes). Although the authors concluded that daily glucose variability was comparable between the two insulin analogs, postprandial glucose was more stable with insulin aspart when given as a normal premeal bolus. Based on their data, the authors of this study recommended that insulin aspart and lispro should be given with a different bolus distribution in order to achieve comparable postprandial glycemic control. In contrast, a study ${ }^{41}$ reviewing the consequences of delayed line change in continuous subcutaneous insulin infusions showed no difference in glucose control between insulin lispro and aspart.

A head-to-head comparison between biphasic formulations of insulin aspart (BIAsp 30: 30\% aspart, 70\% protaminated aspart), biphasic insulin lispro 25 (mix 25; 25\% lispro, $75 \%$ protaminated lispro) and biphasic human insulin 30 (BHI) (30\% human regular insulin, 70\% neutral protamine hagedorn insulin) was done in patients with type 2 diabetes mellitus treated with insulin. Both analogs were injected immediately before the test meal, while BHI was given 15 minutes before the test meal. Both analogs were superior to BHI in terms of serum glucose excursion 0-5 hours after the meal, and BIAsp 30 was superior to lispro mix 25
(16.6 \pm 4.4 versus $18.9 \pm 6.1 \mathrm{mmol} / \mathrm{L} \times$ hour, $P<0.05)$. In this study, glucose excursion during the late postprandial phase was also lower with BIAsp compared with lispro mix $25(8.3 \pm 2.6$ versus $9.7 \pm 3.8 \mathrm{mmol} / \mathrm{L} \times$ hour, $P<0.05)$ but not during the early phase. ${ }^{42}$ It should be borne in mind that the protaminated ratio of the two analogs used in this study was different, and whether the difference was due to this alone, an intrinsic difference between the two analogs, or a combination of the two, is unclear.

\section{Insulin lispro versus glulisine}

In 672 patients with type 1 diabetes mellitus on a basal bolus regimen utilizing glargine as the basal insulin, insulin lispro and glulisine were shown over a 26-week period to achieve a similar reduction in $\mathrm{HbA}_{1 \mathrm{c}}$ (adjusted mean change from baseline $-0.14 \%$ in both groups) as well as no relevant difference between the two groups in reports of symptomatic hypoglycemia $(3.64 \pm 4.49$ [glulisine] versus $3.48 \pm 4.38$ [lispro] events/month). Although this study demonstrated that insulin glulisine achieves glycemic control equivalent to that of insulin lispro, it also showed that the basal insulin dose was relatively unchanged from baseline in the glulisine group but increased in the insulin lispro group (0.12 IU [glulisine] versus $1.82 \mathrm{IU}$ [lispro]; $P=0.0001)$. The clinical significance of this difference remains to be established. ${ }^{43}$ Among pediatric patients with type 1 diabetes mellitus, insulin glulisine has also been shown to be as effective as insulin lispro in baseline-to-endpoint $\mathrm{HbA}_{1 \mathrm{c}}$ change $(0.10 \%$ versus $0.16 \%$, respectively) with similar episodes of symptomatic hypoglycemia. ${ }^{44}$

When administered by insulin pump to patients with type 1 diabetes mellitus, insulin glulisine was not superior to insulin lispro in terms of unexplained hyperglycemia or perceived catheter set occlusion. ${ }^{45}$ Insulin glulisine was also associated with a higher frequency of symptomatic hypoglycemia compared with insulin lispro in patients with type 1 diabetes mellitus which the authors suggested may have been due to overdosing. ${ }^{45}$ When administered preprandially to patients with type 2 diabetes mellitus, insulin glulisine underwent significantly faster absorption than insulin lispro during the first 30 minutes after a meal. ${ }^{46}$ However, this did not translate into overall statistically significant differences in the plasma glucose profile between the two analog insulins.

\section{Insulin lispro in fixed combinations}

In the US, neutral protamine lispro is available premixed with insulin lispro. It comes in two preparations, ie, 
Humalog ${ }^{\circledR} \operatorname{mix} 75 / 25(75 \%$ neutral protamine lispro and $25 \%$ insulin lispro) and Humalog ${ }^{\circledR}$ mix 50/50 (50\% neutral protamine lispro and $50 \%$ insulin lispro). Because premixed insulin contains both basal and prandial components in different proportions, most patients prefer to use it because it can enable twice-daily injections compared with four injections per day for the basal-bolus regimen. Unlike human premixed insulin, which should be injected at least 30 minutes prior to a meal, premixed analog insulin can be injected within 15 minutes of a meal, which is more convenient for some patients.

When compared with human insulin $70 / 30$, lispro $75 / 25$ has been proven to decrease postprandial blood glucose levels and excursion significantly among patients with type 2 diabetes mellitus, which is expected of analogs, as described above. ${ }^{47-49}$ Despite this, premixed insulin lispro was not shown to have an advantage over human insulin $70 / 30$ in reducing $\mathrm{HbA}_{1 \mathrm{c}}$ among patients with type 1 or type 2 diabetes mellitus. ${ }^{12,50}$ However, in a Japanese treat to target study, ${ }^{51}$ it was shown that use of premixed lispro 50/50 was able to decrease $\mathrm{HbA}_{1 \mathrm{c}}$ significantly compared with premixed human insulin (mean $\mathrm{HbA}_{1 \mathrm{c}} 7.59 \% \pm 0.44 \%$ at the start of the study and $7.24 \% \pm 0.49 \%$ at 4 months, $P<0.05$ for the analog group versus mean $\mathrm{HbA}_{1 \mathrm{c}} 7.33 \% \pm 0.58 \%$ at the start of the study and $7.29 \% \pm 0.65 \%$ at 4 months in the premixed human insulin group). A previous study by the same group comparing biphasic insulin aspart 70/30 and human insulin 70/30 did not show a beneficial effect on $\mathrm{HbA}_{1 \mathrm{c}}$ level in insulin-naïve patients. They hypothesized that the difference they were able to show in the second study may have been due to their patient population (ie, Japanese) and a higher consumption of high glycemic index food (ie, rice) that required a greater amount of rapid-acting insulin analog, and that the difference in $\mathrm{HbA}_{1 \mathrm{c}}$ reduction among insulin-naïve patients treated with human insulin or analog may be small and difficult to detect.

Lispro 75/25 given twice a day was shown to be superior to glyburide $15 \mathrm{mg}$ daily in terms of $\mathrm{HbA}_{1 \mathrm{c}}$ reduction $(8.5 \%$ with lispro $75 / 25$ versus $9.4 \%$ with glyburide; $P=0.001) .{ }^{52}$

When compared with once-daily insulin glargine in patients with type 2 diabetes mellitus treated for 16 weeks in treat-to-target trials, lispro 75/25 given twice daily has been shown to be superior in terms of $\mathrm{HbA}_{1 \mathrm{c}}$ reduction $(7.54 \% \pm 0.87 \%$ versus $8.14 \% \pm 1.03 \%, P<0.001)$. A higher proportion of patients ( $42 \%$ versus $18 \% ; P=0.002)$ also met the treatment goal of $\mathrm{HbA}_{1 \mathrm{c}}<7 \%$ with lispro 75/25 given twice daily compared with insulin glargine given once daily. ${ }^{53}$

\section{Use in pregnancy}

In 1997, two cases were reported of a possible teratogenic effect of insulin lispro used in pregnant patients with type 1 diabetes mellitus. ${ }^{54}$ The observations made in these case reports were not made in subsequent studies. Studies that used insulin lispro in patients with type 1,2, or gestational diabetes mellitus have reported no increase in pregnancy complications compared with human regular insulin. ${ }^{55-57}$ One meta-analysis that compared insulin lispro with human regular insulin in patients with type 1 diabetes mellitus found that there was no difference in metabolic control or perinatal outcome among patients who used insulin lispro during pregnancy compared with human regular insulin, aside from a higher rate of large-for-gestational age newborns among those who used insulin lispro during pregnancy (relative risk $1.38 \%$, confidence interval $1.14-1.68) .{ }^{58}$ Comparable or improved glycemic control with a lower total insulin requirement and $\mathrm{HbA}_{1 \mathrm{c}}$ during pregnancy was reported among patients with gestational as well as type 1 and 2 diabetes mellitus. ${ }^{56,57,59}$

\section{Quality of life and cost-effectiveness}

Health-related quality of life is a management outcome variable that has been growing in importance in recent years. Although diabetes mellitus is recognized to be a disease that significantly affects quality of life in our patients, ${ }^{60,61}$ there are scant data on how treatment with insulin analogs modifies it.

The largest and most comprehensive health-related quality of life trial for insulin lispro was a subsection of the original safety and efficacy study done by the Multicenter Insulin Lispro Study Group. ${ }^{62}$ This study compared healthrelated quality of life over 12 months in patients taking insulin lispro with those taking human regular insulin, in the setting of an open-label multinational randomized trial involving 468 patients with type 1 diabetes mellitus and 474 with type 2 diabetes mellitus. It showed that, for patients with type 1 diabetes mellitus, there was no statistically significant difference in outcomes, except in the domains of treatment satisfaction and treatment flexibility. In the case of patients with type 2 diabetes mellitus, there was no difference in any domain between the two therapies.

A much smaller $(n=30)$ randomized controlled trial compared twice-daily premixed human insulin versus the equivalent insulin lispro formulation. ${ }^{51} \mathrm{~A}$ similar improvement in treatment convenience score was found, with no difference in quality of life data, although the follow-up time was much shorter (4 months). 
Lastly, a follow-up of the ABCs of Diabetes study ${ }^{63}$ evaluated the effect that treatment with insulin lispro had on quality of life in adolescents who were unable to maintain metabolic control with human regular insulin. It was found that adolescents in the insulin lispro group had significantly better diabetes self-efficacy and quality of life, but that satisfaction with diabetes treatment was not associated with use of insulin lispro. In the last two studies, it is clear that issues with a small sample size could have affected their discriminative capacity, making a type 2 error a significant possibility.

Another important aspect in the evaluation of new medications is their cost-effectiveness, even moreso in the current cost-conscious health care environment. Few studies have looked at this issue in regards to rapid-acting insulin analogs, but recent studies have shed some light on it.

A cost-effectiveness study applying the Center for Outcomes Research Diabetes Model to data obtained from metaanalysis of randomized controlled trials showed that, for type 1 diabetes mellitus, use of insulin lispro had an increased efficiency that was associated with an incremental cost of almost 30,000 Canadian dollars per quality-adjusted life-year. ${ }^{64}$ When the model was adjusted by including fear of hypoglycemia, the cost decreased to less than 2000 Canadian dollars.

The analysis was repeated for type 2 diabetes mellitus, showing increased effectiveness for insulin lispro, but an even larger cost per quality-adjusted life-year (around 130,000 dollars). The authors did caution that the model was very sensitive to variations in the level of fear of hypoglycemia or in the difference in $\mathrm{HbA}_{1 \mathrm{c}}$ between the treatments, so any decisions made on the basis of these data have to take this into account.

One large objection to the previous approach is that subjects in randomized controlled trials may be very different from subjects who are seen in the day-to-day clinics. Also, there are clear differences in the types of patients who receive one type of insulin versus another, and this can clearly change the parameters when comparing the costs associated with each type of insulin. A study conducted using pharmacy claims data from 14 plans distributed over the US tried to avoid this by using a propensity score. ${ }^{65}$ This score, which indicates how likely a particular patient is to receive one type of therapy versus another, was used to match patients and balance the treatment groups at the start of the study. Over the course of a 12-month follow-up of 3664 subjects, it was found that patients using insulin lispro made significantly more office visits and filled more prescriptions compared with patients using human regular insulin. At the same time, these patients had significantly fewer inpatient hospitalizations than the group of patients on human regular insulin. The total cost of all interventions (both inpatient and outpatient) showed cost savings for the insulin lispro group of 216 dollars (which was not found to be statistically significant). One significant limitation of this study is that they included patients in each insulin group if they had only one prescription filled for insulin during their time of participation in the study.

A later study by the same group, using data from a large managed care organization, tried to replicate the above results, while addressing the main concerns about the previous study. ${ }^{66}$ This was done by including patients who had at least three refills of insulin, and by stratifying the patients depending on their propensity score (instead of only matching them by score). A total of 6436 patients were followed in this way for 12 months, and a similar pattern of a greater number of physician office visits was found in patients using insulin lispro, along with a larger total pharmacy cost (which was expected, given that insulin lispro is more expensive than human regular insulin), but a lower total medical cost (2327 dollars) which was not found to be statistically significant. It is important to note that one limitation of the propensity score methodology is that factors that are not measured can significantly affect the scores obtained. Taking all these factors into account, insulin lispro seems to have an effectiveness similar or superior to that of human regular insulin, with an associated increase in cost that may be compensated by a lower number of hospitalizations.

\section{Conclusion}

Since its introduction in 1996, insulin lispro and other rapidacting analogs have proven to be safe and comparable or superior to human regular insulin in terms of $\mathrm{HbA}_{1 \mathrm{c}}$ reduction and/or reducing the risk of hypoglycemia. The rapid onset of action of insulin lispro and the other analogs allows their injection around meal time, making them safer and easier to use in comparison with human regular insulin.

\section{Disclosure}

None of the authors of this paper have any relevant financial or any other type of conflict of interest to disclose in this work.

\section{References}

1. Brems DN, Alter LA, Beckage MJ, et al. Altering the association properties of insulin by amino acid replacement. Protein Eng. 1992;5(6):527-533.

2. Howey DC, Bowsher RR, Brunelle RL, Woodworth JR. Lys(B28), pro(B29)-human insulin. A rapidly absorbed analogue of human insulin. Diabetes. 1994;43(3):396-402. 
3. Oiknine R, Bernbaum M, Mooradian AD. A critical appraisal of the role of insulin analogues in the management of diabetes mellitus. Drugs. 2005;65(3):325-340

4. Kurtzhals P, Schaffer L, Sorensen A, et al. Correlations of receptor binding and metabolic and mitogenic potencies of insulin analogs designed for clinical use. Diabetes. 2000;49(6):999-1005.

5. Hedman CA, Lindstrom T, Arnqvist HJ. Direct comparison of insulin lispro and aspart shows small differences in plasma insulin profiles after subcutaneous injection in type 1 diabetes. Diabetes Care 2001;24(6):1120-1121.

6. von Mach MA, Brinkmann C, Hansen T, Weilemann LS, Beyer J. Differences in pharmacokinetics and pharmacodynamics of insulin lispro and aspart in healthy volunteers. Exp Clin Endocrinol Diabetes. 2002;110(8):416-419.

7. Plank J, Wutte A, Brunner G, et al. A direct comparison of insulin aspart and insulin lispro in patients with type 1 diabetes. Diabetes Care. 2002;25(11):2053-2057

8. Homko C, Deluzio A, Jimenez C, Kolaczynski JW, Boden G. Comparison of insulin aspart and lispro: pharmacokinetic and metabolic effects. Diabetes Care. 2003;26(7):2027-2031.

9. Chao M, Wang W, Zhang Y, Lu X, Meng J, Ning G. Bioequivalence between two human insulin analogs in chinese population: glulisine and lispro. Endocrine. 2010;38(1):48-52.

10. Heise T, Nosek L, Spitzer H, et al. Insulin glulisine: a faster onset of action compared with insulin lispro. Diabetes Obes Metab. 2007;9(5):746-753.

11. Radziuk JR, Bradley B, Welsh L, De Felippis, Roach P. Neutral protamine lispro: Activity profile of s.c. administration with and without admixture of soluble lispro (Abstr 849). Diabetologia. 1996 39(1 Suppl 1):A224.

12. Roach P, Woodworth JR. Clinical pharmacokinetics and pharmacodynamics of insulin lispro mixtures. Clin Pharmacokinet. 2002;41(13):1043-1057.

13. Heise T, Weyer C, Serwas A, et al. Time-action profiles of novel premixed preparations of insulin lispro and NPL insulin. Diabetes Care. 1998;21(5):800-803.

14. Slieker LJ, Sundell K. Modifications in the $28-29$ position of the insulin B-chain alter binding to the IGF-I receptor with minimal effect on insulin receptor binding. (Abstr 670). Diabetes. 1991;(40 Suppl 1): 168A.

15. Slieker LJ, Brooke GS, Chance RE. Insulin and IGF-I analogs: Novel approaches to improved insulin pharmacokinetics. In: Current Directions in Insulin-Like Growth Factor Research, in Advances in Experimental Medicine and Biology (LeRoith D and Raizada MK editors) 1994;343:25-32.

16. Monnier L, Lapinski H, Colette C. Contributions of fasting and postprandial plasma glucose increments to the overall diurnal hyperglycemia of type 2 diabetic patients: Variations with increasing levels of $\mathrm{HbA}(1 \mathrm{c})$ Diabetes Care. 2003;26(3):881-885.

17. Heinemann L. Do insulin-treated diabetic patients use an injectionmeal-interval in daily life? Diabet Med. 1995;12(5):449-450.

18. Anderson JH Jr, Brunelle RL, Koivisto VA, et al. Reduction of postprandial hyperglycemia and frequency of hypoglycemia in IDDM patients on insulin-analog treatment. Multicenter Insulin Lispro Study Group. Diabetes. 1997;46(2):265-270.

19. Pfutzner A, Kustner E, Forst T, et al. Intensive insulin therapy with insulin lispro in patients with type 1 diabetes reduces the frequency of hypoglycemic episodes. Exp Clin Endocrinol Diabetes. 1996;104(1):25-30.

20. Brunelle BL, Llewelyn J, Anderson JH Jr, Gale EA, Koivisto VA. Meta-analysis of the effect of insulin lispro on severe hypoglycemia in patients with type 1 diabetes. Diabetes Care. 1998;21(10):1726-1731.

21. Raskin P, Guthrie RA, Leiter L, Riis A, Jovanovic L. Use of insulin aspart, a fast-acting insulin analog, as the mealtime insulin in the management of patients with type 1 diabetes. Diabetes Care. 2000;23(5):583-588.

22. Gough SC. A review of human and analogue insulin trials. Diabetes Res Clin Pract. 2007;77(1):1-15.
23. Gale EA. A randomized, controlled trial comparing insulin lispro with human soluble insulin in patients with type 1 diabetes on intensified insulin therapy. The UK Trial Group. Diabet Med. 2000;17(3): 209-214.

24. Altuntas Y, Ozen B, Ozturk B, et al. Comparison of additional metforminutes or NPH insulin to mealtime insulin lispro therapy with mealtime human insulin therapy in secondary OAD failure. Diabetes Obes Metab. 2003;5(6):371-378.

25. Bastyr EJ 3rd, Stuart CA, Brodows RG, et al. Therapy focused on lowering postprandial glucose, not fasting glucose, may be superior for lowering HbA1c. IOEZ study group. Diabetes Care. 2000;23(9):1236-1241.

26. Bastyr EJ 3rd, Johnson ME, Trautmann ME, Anderson JH Jr, Vignati L. Insulin lispro in the treatment of patients with type 2 diabetes mellitus after oral agent failure. Clin Ther. 1999;21(10):1703-1714.

27. Siebenhofer A, Plank J, Berghold A, et al. Short acting insulin analogues versus regular human insulin in patients with diabetes mellitus. Cochrane Database Syst Rev. 2006;2:CD003287.

28. Garg S, Ampudia-Blasco FJ, Pfohl M. Rapid-acting insulin analogues in basal-bolus regimens in type 1 diabetes mellitus. Endocr Pract. 2010;16(3):486-505.

29. Hermansen K, Fontaine P, Kukolja KK, Peterkova V, Leth G, Gall MA. Insulin analogues (insulin detemir and insulin aspart) versus traditional human insulins (NPH insulin and regular human insulin) in basal-bolus therapy for patients with type 1 diabetes. Diabetologia. 2004;47(4):622-629.

30. Ashwell SG, Amiel SA, Bilous RW, et al. Improved glycaemic control with insulin glargine plus insulin lispro: A multicentre, randomized, cross-over trial in people with type 1 diabetes. Diabet Med. 2006;23(3):285-292.

31. Murphy NP, Keane SM, Ong KK, et al. Randomized cross-over trial of insulin glargine plus lispro or NPH insulin plus regular human insulin in adolescents with type 1 diabetes on intensive insulin regimens. Diabetes Care. 2003;26(3):799-804.

32. Heller SR, Amiel SA, Mansell P. Effect of the fast-acting insulin analog lispro on the risk of nocturnal hypoglycemia during intensified insulin therapy. UK Lispro Study Group. Diabetes Care. 1999;22(10):1607-1611.

33. Garg SK, Anderson JH, Gerard LA, et al. Impact of insulin lispro on HbA1c values in insulin pump users. Diabetes Obes Metab. 2000;2(5):307-311.

34. Raskin P, Holcombe JH, Tamborlane WV, et al. A comparison of insulin lispro and buffered regular human insulin administered via continuous subcutaneous insulin infusion pump. $J$ Diabetes Complications. 2001;15(6):295-300.

35. Bode B, Weinstein R, Bell D, et al. Comparison of insulin aspart with buffered regular insulin and insulin lispro in continuous subcutaneous insulin infusion: A randomized study in type 1 diabetes. Diabetes Care. 2002;25(3):439-444.

36. Renner R, Pfutzner A, Trautmann M, Harzer O, Sauter K, Landgraf R. Use of insulin lispro in continuous subcutaneous insulin infusion treatment. Results of a multicenter trial. German Humalog-CSII Study Group. Diabetes Care. 1999;22(5):784-788.

37. Melki V, Renard E, Lassmann-Vague V, et al. Improvement of HbAlc and blood glucose stability in IDDM patients treated with lispro insulin analog in external pumps. Diabetes Care. 1998;21(6):977-982.

38. Attia N, Jones TW, Holcombe J, Tamborlane WV. Comparison of human regular and lispro insulins after interruption of continuous subcutaneous insulin infusion and in the treatment of acutely decompensated IDDM. Diabetes Care. 1998;21(5):817-821.

39. Guerra YS, Lacuesta EA, Yrastorza R, Miernik J, Shakya N, Fogelfeld L. Insulin injections in relation to meals in the hospital medicine ward: Comparison of 2 protocols. Endocr Pract. 2011;17(5):737-746.

40. Bartolo PD, Pellicano F, Scaramuzza A, et al. Better postprandial glucose stability during continuous subcutaneous infusion with insulin aspart compared with insulin lispro in patients with type 1 diabetes. Diabetes Technol Ther. 2008;10(6):495-498. 
41. Thethi TK, Rao A, Kawji H, et al. Consequences of delayed pump infusion line change in patients with type 1 diabetes mellitus treated with continuous subcutaneous insulin infusion. J Diabetes Complications. 2010;24(2):73-78.

42. Hermansen K, Colombo M, Storgaard H, Ostergaard A, Kolendorf K, Madsbad S. Improved postprandial glycemic control with biphasic insulin aspart relative to biphasic insulin lispro and biphasic human insulin in patients with type 2 diabetes. Diabetes Care. 2002;25(5):883-888.

43. Dreyer M, Prager R, Robinson A, et al. Efficacy and safety of insulin glulisine in patients with type 1 diabetes. Horm Metab Res. 2005;37(11):702-707.

44. Philotheou A, Arslanian S, Blatniczky L, Peterkova V, Souhami E, Danne T. Comparable efficacy and safety of insulin glulisine and insulin lispro when given as part of a basal-bolus insulin regimen in a 26-week trial in pediatric patients with type 1 diabetes. Diabetes Technol Ther. 2011;13(3):327-334.

45. van Bon AC, Bode BW, Sert-Langeron C, DeVries JH, Charpentier G. Insulin glulisine compared with insulin aspart and to insulin lispro administered by continuous subcutaneous insulin infusion in patients with type 1 diabetes: A randomized controlled trial. Diabetes Technol Ther. 2011;13(6):607-614.

46. Luzio S, Peter R, Dunseath GJ, Mustafa L, Owens DR. A comparison of preprandial insulin glulisine versus insulin lispro in people with type 2 diabetes over a 12-h period. Diabetes Res Clin Pract. 2008;79(2):269-275.

47. Mattoo V, Milicevic Z, Malone JK, et al. A comparison of insulin lispro Mix25 and human insulin 30/70 in the treatment of type 2 diabetes during Ramadan. Diabetes Res Clin Pract. 2003;59(2):137-143.

48. Coscelli C, Iacobellis G, Calderini C, et al. Importance of premeal injection time in insulin therapy: Humalog Mix25 is convenient for improved post-prandial glycemic control in type 2 diabetic patients with Italian dietary habits. Acta Diabetol. 2003;40(4):187-192.

49. Herz M, Arora V, Campaigne BN, Scholtz HE, Potgieter MA, Mollentze W. Humalog Mix25 improves 24-hour plasma glucose profiles compared with the human insulin mixture 30/70 in patients with type 2 diabetes mellitus. S Afr Med J. 2003;93(3):219-223.

50. Roach P, Yue L, Arora V. Improved postprandial glycemic control during treatment with humalog Mix25, a novel protamine-based insulin lispro formulation. Humalog Mix25 Study Group. Diabetes Care. 1999;22(8):1258-1261.

51. Yamada S, Watanabe M, Kitaoka A, et al. Switching from premixed human insulin to premixed insulin lispro: A prospective study comparing the effects on glucose control and quality of life. Intern Med. 2007;46(18):1513-1517.

52. Roach, Koledova E, Metcalfe S, Hultman C, Milicevic Z; Romania/ Russia Mix25 Study Group. Glycemic control with humalog Mix25 in type 2 diabetes inadequately controlled with glyburide. Clin Ther. 2001;23(10):1732-1744.
53. Malone JK, Kerr LF, Campaigne BN, Sachson RA, Holcombe JH; Lispro Mixture-Glargine Study Group. Combined therapy with insulin lispro mix $75 / 25$ plus metformin or insulin glargine plus metformin: A 16-week, randomized, open-label, crossover study in patients with type 2 diabetes beginning insulin therapy. Clin Ther. 2004;26(12):2034-2044.

54. Diamond T, Kormas N. Possible adverse fetal effect of insulin lispro. N Engl J Med. 1997;337(14):1009.

55. Durnwald CP, Landon MB. A comparison of lispro and regular insulin for the management of type 1 and type 2 diabetes in pregnancy. J Matern Fetal Neonatal Med. 2008;21(5):309-313.

56. Bhattacharyya A, Brown S, Hughes S, Vice PA. Insulin lispro and regular insulin in pregnancy. QJM. 2001;94(5):255-260.

57. Aydin Y, Berker D, Direktor N, et al. Is insulin lispro safe in pregnant women: Does it cause any adverse outcomes on infants or mothers? Diabetes Res Clin Pract. 2008;80(3):444-448.

58. Blanco CG, Ballesteros AC, Saladich IG, Pla RC. Glycemic control and pregnancy outcomes in women with type 1 diabetes mellitus using lispro versus regular insulin: A systematic review and meta-analysis. Diabetes Technol Ther. 2011;13(9):907-911.

59. Jovanovic L, Ilic S, Pettitt DJ, et al. Metabolic and immunologic effects of insulin lispro in gestational diabetes. Diabetes Care. 1999;22(9):1422-1427.

60. Rubin RR, Peyrot M. Quality of life and diabetes. Diabetes Metab Res Rev. 1999;15(3):205-218.

61. Singh H. Quality of life in diabetes. Int $J$ Diabetes Dev Ctries. 2006;26(1):7-10.

62. Kotsanos JG, Vignati L, Huster W, et al. Health-related quality-of-life results from multinational clinical trials of insulin lispro. assessing benefits of a new diabetes therapy. Diabetes Care. 1997;20(6):948-958.

63. Grey M, Boland EA, Tamborlane WV. Use of lispro insulin and quality of life in adolescents on intensive therapy. Diabetes Educ. 1999;25(6):934-941.

64. Cameron CG, Bennett HA. Cost-effectiveness of insulin analogues for diabetes mellitus. CMAJ. 2009;180(4):400-407.

65. Hall JA, Summers KH, Obenchain RL. Cost and utilization comparisons among propensity score-matched insulin lispro and regular insulin users. J Manag Care Pharm. 2003;9(3):263-268.

66. Chen K, Chang EY, Summers KH, Obenchain RL, Yu-Isenberg KS, Sun P. Comparison of costs and utilization between users of insulin lispro versus users of regular insulin in a managed care setting. J Manag Care Pharm. 2005;11(5):376-382.

67. Holleman MD, Hoekstrra JBL. Insulin Lispro. $N$ Engl J Med. 1997;337:176-183.

\section{Publish your work in this journal}

Diabetes, Metabolic Syndrome and Obesity: Targets and Therapy is an international, peer-reviewed open-access journal committed to the rapid publication of the latest laboratory and clinical findings in the fields of diabetes, metabolic syndrome and obesity research. Original research, review, case reports, hypothesis formation, expert opinion and commentaries are all considered for publication. The manuscript management system is completely online and includes a very quick and fair peer-review system, which is all easy to use. Visit http://www.dovepress.com/testimonials.php to read real quotes from published authors. 